\title{
PENERAPAN TEKNOLOGI HIDROAKUSTIK DI BIDANG ILMU DAN TEKNOLOGI KELAUTAN
}

\section{Oleh}

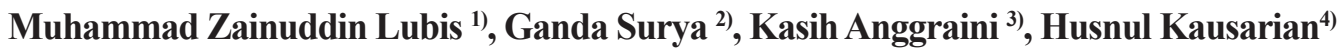

\section{ABSTRACT}

\begin{abstract}
APPLICATION OF FIELD HYDROACOUSTIC TECHNOLOGY FOR MARINE SCIENCE AND TECHNOLOGY Utilization hydroacoustic methods in recent years have become increasingly effective for estimating the abundance of marine fish, especially fish stocks, where is impossible to do with conventional methods approach. Widely hydroacoustic technology has been used to map and classify the content of the resource base of waters and benthic animals that are on the bottom, type of substrate and benthic biota. Target Strength (TS) is the most important factor in the detection and prediction of fish stocks by using hydroacoustic. The TS is a measure that can describe the ability of a target to reflect sound waves that come about it. In the propagation of sound waves, the amount of energy per second will be flowing through the unit certain area perpendicular to the direction of propagation. The amount of energy per second crossing a certain area of the unit refers to as the intensity of the wave. The system of detection and measurement of underwater involves three components, namely medium, targets, and equipment. Sonar equation is built based on the similarity or balance between the parts of the received signal, the desired (called signal) and the unwanted parts (referred noise or noise), depending on the specific sonar functions are applied.
\end{abstract}

\section{PENDAHULUAN}

\section{Hidroakustik}

Perkembangan terkini di bidang sains perikanan, teknologi akustik, pengolahan sinyal digital dan pengolahan citra digital, memiliki kemajuan yang sangat cepat dibidang teknologi informasi tersebut untuk melakukan identifikasi kawanan ikan dengan sinyal akustik. Beberapa peneliti sudah mengembangkannya menjadi informasi karakteristik kawanan ikan dengan digitalisasi sinyal hambur balik (back-scattered). Bahkan dapat membedakan antar spesies ikan di lingkungan sub tropis, dengan berbagai tingkat kesuksesan (Coetzee, 2000).

Metode Hidroakustik memiliki beberapa metode, salah satunya adalah sistem single beam echo sounder. Sistem ini merupakan alat ukur kedalaman pada

\footnotetext{
1) Dosen Teknik Geomatika, Politeknik Negeri Batam (zainuddinlubis@polibatam.ac.id)

2) Mahasiswa Teknik Geomatika, Politeknik Negeri Batam

3) Pusat Penelitian Oseanografi LIPI

4) Teknik Geologi, Fakultas Tenik, Universitas Islam Riau (UIR)
} 
medium air yang menggunakan sistem pancaran tunggal sebagai pengirim dan penerima sinyal gelombang suara, dapat mengukur kedalaman air secara langsung dari kapal survei (Bozzano et al., 2008). Secara umum single beam mempunyai komponen alat transceiver (tranducer/reciever) pada lambung kapal atau sisi bantalan pada kapal. Transciever mengirimkan pulsa akustik dengan frekuensi tertentu yang terkandung dalam beam (sorot/pancaran) secara langsung menyusuri bawah kolom air selama di jalur pemeruman (Becker \& Sandwell, 2008). Pada tahun 1960an dan 1970an telah dilakukan survei pemeruman menggunakan metode akustik dengan 2 sistem (single beam dan multi beam) di perairan antar benua, dan hasilnya banyak wilayah perairan yang belum dapat terjangkau oleh kapal survei tesebut. Pengukuran kedalaman menggunakan kapal akan membatasi luasan area survei, karena apabila kapal mendekati wilayah pesisir atau pantai dengan kondisi kedalaman sangat dangkal akan dapat mengakibatkan kapal kandas. Pengukuran menggunakan metode akustik memerlukan biaya dan waktu yang sesuai dengan luasan area survei. Oleh karena itu, semakin luas area tersebut, maka akan semakin banyak biaya dan semakin lama waktu yang dibutuhkan (Lubis et al., 2016).

Menurut Pujiyati (2008), metode hidroakustik merupakan metode deteksi objek bawah air menggunakan peralatan transduser yang menghasilkan gelombang suara. Gelombang suara tersebut kemudian merambat di medium air, dan pada saat membentur objek, maka gelombang suara selanjutnya dipantulkan kembali dalam bentuk gema (echo) untuk dianalisis lebih lanjut (Lubis \& Anurogo, 2016, Lubis \& Manik, 2017).

Pemanfaatan metode hidroakustik dalam beberapa tahun terakhir ini menjadi semakin efektif untuk mengestimasi kelimpahan stok ikan, dimana tidak mungkin dapat dilakukan dengan pendekatan metode konvesional. Kelemahan-kelemahan yang ada dalam metode pendugaan secara konvesional, dapat diatasi melalui penggunaan metode hidroakustik. Menurut MacLennan \& Simmonds (1992), metode ini memiliki beberapa keunggulan di dalam mengestimasi schooling ikan dan kelimpahannya, antara lain informasi yang dihasilkan lebih cepat dan meliputi area yang lebih luas, pendugaan atau estimasi stok dapat dilakukan secara insitu dan real time tanpa bergantung dari data statistik perikanan, memiliki ketelitian dan ketepatan tinggi, dapat dipakai ketika metode lain tidak dapat digunakan dan tidak berbahaya atau merusak, karena frekuensi suara yang digunakan tidak membahayakan bagi pengguna maupun target survei.

Dalam upaya untuk meningkatkan produktivitas penangkapan ikan nelayan, maka perlu dilakukan proses modernisasi pada kapal-kapal nelayan, salah satunya adalah dengan memasang alat-alat berteknologi akustik pada alat penangkap ikannya (Pasaribu, 1982). Bidang teknologi akustik semakin canggih dan sangat berguna selama bertahun-tahun. Biasanya teknologi akustik menggunakan 
sonar, kita akan dapat menduga volume air dalam waktu singkat, akustik echo dari ikan, mendeteksi lokasi dan jumlah dari ikan tersebut, menduga tingkah laku ikan tersebut (Simmonds \& MacLennan, 2008). Teknologi akustik bawah air yang dimaksud ini adalah echo sounder. Echo Sounder pertama kali digunakan pada saat eksplorasi Meteor (1927-1929) di Jerman pada saat pemetaan wilayah Atlantik Selatan. Pemetaan secara sistematis pada deep-ocean basin dimulai pada akhir tahun 1940-an. Oleh karena itu, suatu wilayah yang luas dapat diselidiki dengan mudah (Zhang \& Xu, 1993).

Teknologi hidroakustik memanfaatkan pencarian bawah laut dengan suara yang kuat untuk mendeteksi, meng amati dan menghitung parameter fisik dan biologi. Teknologi hidroakustik merupakan metode yang populer digunakan selama bertahun-tahun dalam survei sumber daya perikanan. Penelitian di bidang hidroakustik terus mengalami perkembangan yang signifikan. Berdasarkan teori dan formula hidroakustik, teknik ini sekarang sedang diadopsi untuk melakukan survei terumbu karang. Adan- ya kebutuhan teknologi menggunakan sitem hidroakustik yang terus meningkat yang berfungsi mengklasifikasi dan memetakan ekosistem laut di berbagai skala spasial dalam mendukung ilmu pengetahuan berbasis ekosistem untuk pengelolaan laut (Anderson et al., 2008). Teknologi hidroakustik telah banyak digunakan untuk memetakan dan mengklasifikasikan dasar perairan dan kandungan sumberdaya hewan bentik yang ada di dasar perairan, tipe substrat dan biota bentik. Perkembangan dalam mengklasifikasikan substrat dasar perairan dan vegetasi bawah air membuat hidroakustik sebagai alat yang efektif untuk memantau dan pemetaan parameter habitat di ekosistem air. Selain itu, dengan menggunakan teknologi hidroakustik dapat membedakan dan mengelompokkan berbagai tipe substrat dasar perairan. Perbedaan tipe dasar perairan dapat digambarkan melalui tingkat kekasaran (roughness) dan kekerasan (hardness) dasar perairan seperti batu, pasir, lumpur atau campurannya (Pujiyati et al., 2010). Komponen utama dan prinsip kerja echo sounder dapat dilihat pada Gambar 1 dan Gambar 2.

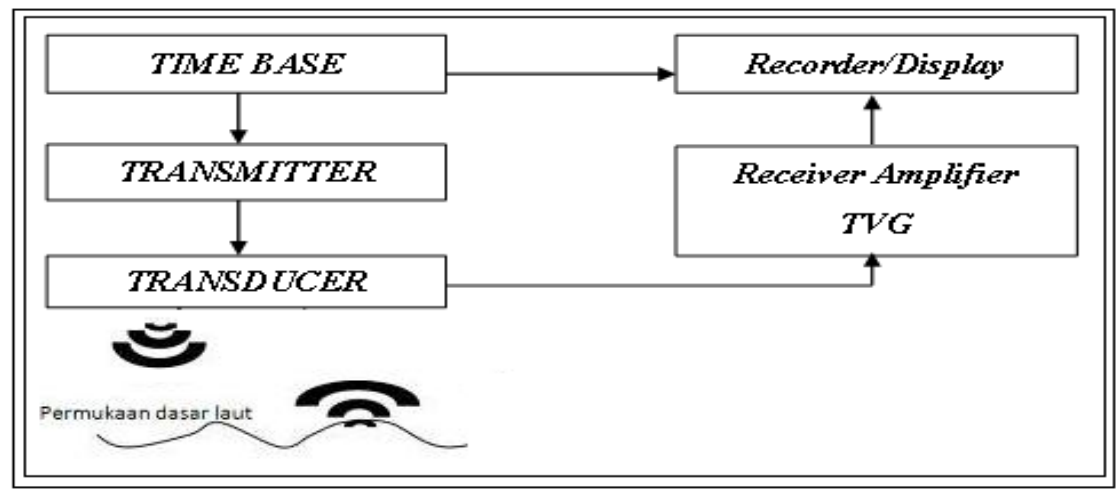

Gambar 1. Komponen utama dan prinsip dasar echo sounder (Johannesson \& Mitson 1983) 


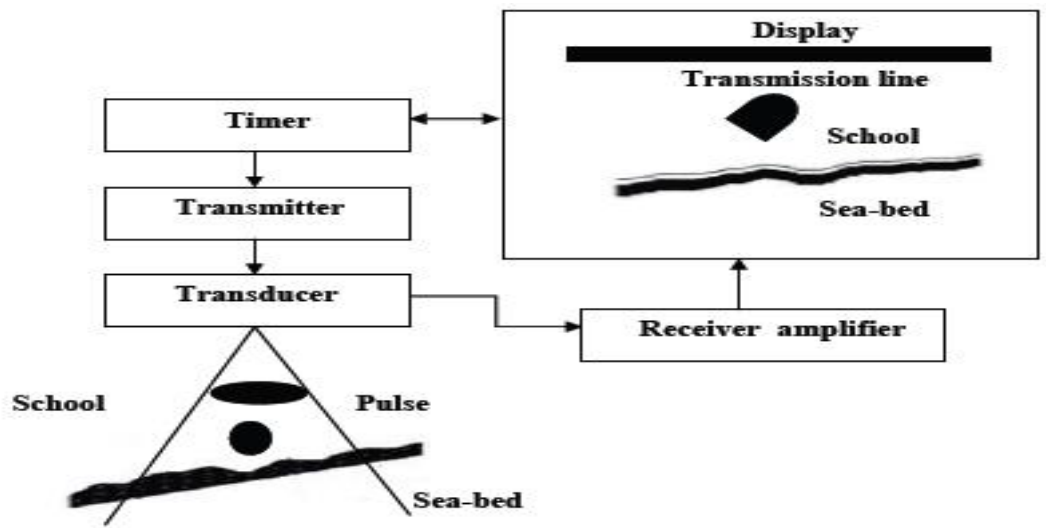

Gambar 2. Prinsip kerja Single Beam Echo Sounder (MacLennan \& Simmonds, 2005)

FAKTOR-FAKTOR YANG BERPERAN MEMPENGARUHI NILAI TARGET STRENGTH (TS) IKAN

Target Strength (TS) secara umum dapat dipengaruhi oleh tiga faktor, yaitu faktor target itu sendiri, faktor lingkungan, dan faktor instrumen akustik. Faktor target meliputi ukuran, anatomi ikan, gelembung renang, tingkah laku dari orientasi (Priatna, 2011). Faktor- faktor target tersebut adalah:

\section{Ukuran Ikan}

Hubungan antara ukuran ikan dengan nilai TS, sangat bervariasi tergantung kepada spesiesnya. Umumnya untuk spesies ikan, semakin besar ukuran ikan semakin besar nilai TS nya. Hal ini terutama berlaku untuk geometrical region dari grafik hubungan antara ukuran target dan TS, untuk region, resonance, resonance region dan transition region, kecenderungan hubungan tersebut tidak berlaku (Johanneson \& Mitson 1983). Anatomi seperti kepala, badan, ekor dan sirip memiliki pantulan suara yang berbeda.
Demikian juga dengan lambung, usus, hati, tulang, daging dan insang mempunyai berat jenis $(\rho)$ dan kecepatan suara (c) yang berbeda, sehingga secara akustik akan mempunyai kemampuan memantulkan suara yang berbeda.

\section{Gelembung Renang}

Secara akustik, ikan dan organisme laut dibagi dalam dua kelompok besar, yaitu blader fish (mempunyai gelembung renang), dan juga akan terbagi kepada kelompok ikan-ikan yang mempunyai gelembung renang pada umumnya tidak memiliki TS maksimum tepat pada dorsal aspect, sedangkan ikan yang tidak memiliki gelembung renang dengan nilai maksimum TS umumnya tepat pada dorsal aspect. Nilai TS ikan yang mempunyai gelembung renang (Furusawa 1998). Menurut (Yasuma et al., 2003) hasil sudut yang dihasilkan dari ikan yang memiliki gelembung renang. Gambar geometri gelembung renang untuk model Soft Spheroid dapat dilihat pada Gambar 3. 


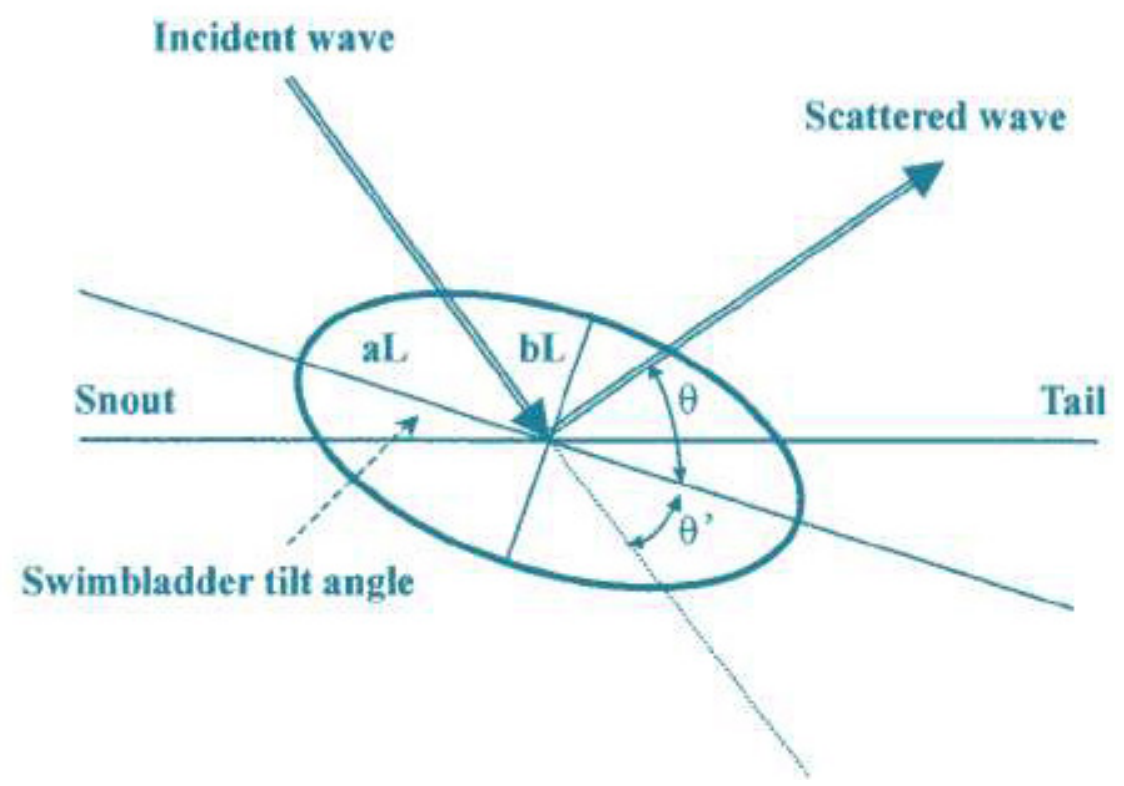

Gambar 3. Geometri gelembung renang untuk model Soft Spheroid (Yasuma et al., 2003)

\section{TINGKAH LAKU / ORIENTASI IKAN}

Hasil penelitian yang dilakukan oleh Misund (1997) menyatakan bahwa nilai Target Strength (TS) sangat ditentukan oleh orientasi ikan, terutama kemiringan tubuh untuk garis hubung antara kepala dan ekor. Orientasi ikan akan meliputi tilting, dan rolling beserta yawing. Yawing tidak berpengaruh, karena umumnya transducer berbentuk bulat, sehingga posisi ikan tidak menimbulkan perubahan sudut, jika dilihat dari transducer. Sedangkan untuk rolling tidak berpengaruh nyata, karena ikan yang mempunyai gelembung renang sebagian energi yang dipantulkan berasal dari gelembung renang, dan bukan berasal dari dorsal aspect. Tillting menimbulkan perubahan sudut posisi di transducer, baik untuk ikan yang mempunyai gelembung renang maupun tidak (Arnaya, 1991).

\section{TARGET STRENGTH (TS)}

Target Strength (TS) adalah faktor yang terpenting dalam pendeteksian dan pendugaan stok ikan dengan menggunakan metode hidroakustik. TS merupakan suatu ukuran yang dapat menggambarkan kemampuan suatu target untuk memantulkan gelombang suara yang datang mengenainya. Nilai TS suatu ikan tergantung kepada ukuran dan bentuk tubuh, sudut datang pulsa, tingkah laku atau orientasi ikan terhadap tranducer, keberadaan gelembung renang, frekuensi atau panjang gelombang, acoustic impedance dan elemen ikan (daging, tulang, kekenyalan kulit, serta distribusi dari sirip dan ekor), walaupun pengaruh elemen terakhir ini sangat kecil, karena nilai kerapatannya tidak terlalu jauh dengan air (Simmonds \& McLennan, 2005). 
Menurut Tobito (1990), TS adalah ukuran desibel intensitas suara yang dikembalikan oleh target, dan diukur pada jarak standar satu meter dari pusat target relatif terhadap intensitas suara yang mengenai target. Johannesson \& Mitson (1983) membagi dua definisi TS berdasarkan domain yang digunakan, yaitu intensitas target strength (TSi), dan energi target strength (TSe). Berdasarkan intensitas target strength dapat diformulasikan sebagai berikut:

$\mathrm{TSi}=10 \log , \mathrm{r}=1 \mathrm{~m}$

dimana:

TSi : Intensitas target strength

Ir : Intensitas suara yang dipantulkan diukur pada jarak 1 meter dari target

Ii : Intensitas suara yang mengenai target

Adapun energi target strength diformulasikan sebagai :

$\mathrm{TSe}=10 \log , \mathrm{r}=1 \mathrm{~m}$

TSe : Energi target strength

Er : Energi suara yang dipantulkan di ukur pada jarak 1 meter dari target

Ei : Energi suara yang mengenai target

Menurut Maclennan \& Simmond (2005), TS merupakan back scattering cross section dari target yang mengembalikan sinyal, dan dinyatakan dalam bentuk persamaan:

$\mathrm{TS}=10 \log$,

Adapun menurut Burczynski \& Johnson (1986) kesetaraan back scattering cross section () dengan TS dinyatakan dalam persamaan:
$\mathrm{TS}=10 \log$

TS ikan tunggal yang berperan sebagai scalling factor bagi volume backscattering strength kelompok ikan agar diperoleh pendugaan kelimpahan ikan, pendugaan baik ukuran maupun densitas ikan selalu tergantung pada distribusi target strength.

\section{SISTEM SONAR}

Sistem SONAR (Sound Navigation and Ranging), akan menghasilkan suara yang terbentuk dari gerakan molekul suatu bahan elastis. Oleh karena bahan tersebut elastis, maka gerak partikel dari bahan sumber suara akan memicu gerak partikel di dekatnya. Gerak partikel sejajar dengan arah perambatan ketika di dalam medium air (Jaya, 2011). Gerak air bersifat kompresibel ini menyebabkan perubahan tekanan yang dapat dideteksi oleh hidrofon yang peka terhadap tekanan. Tekanan gelombang suara ini berhubungan dengan kecepatan partikel fluida. Gelombang suara yang merambat dalam air membawa energi mekanik dalam bentuk energi kinetik dari partikel yang sedang bergerak ditambah dengan energi potensial yang ada dalam medium elastis. Dalam perambatan gelombang suara, sejumlah energi per detik akan mengalir melewati satuan luasan tertentu yang tegak lurus dengan arah perambatan. Jumlah energi per detik yang melintasi satuan luasan tertentu disebut sebagai intensitas gelombang. Umumnya, satuan intensitas suara dinyatakan dalam dB (desibel). Gambar 4 Sistem penggambaran dalam geometri. 


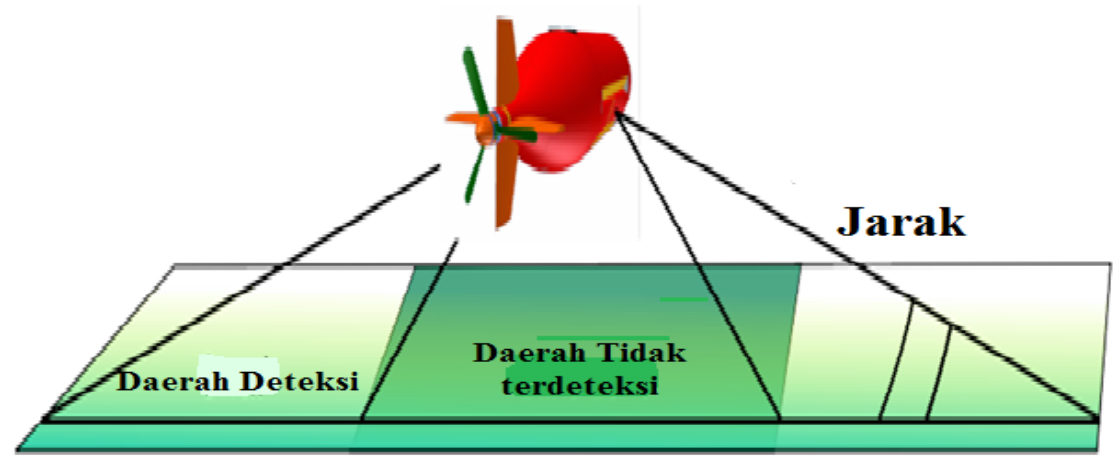

Gambar 4. Sistem penggambaran dalam geometri (Hansen, 2011).

Secara sederhana, sistem deteksi dan pengukuran bawah air melibatkan tiga komponen, yakni medium, target, dan peralatan. Persamaan sonar dibangun berdasarkan kesamaan atau keseimbangan antara bagian dari sinyal yang diterima, yang diinginkan (disebut sinyal) dan bagian yang tidak diinginkan (disebut derau atau noise), tergantung fungsi sonar tertentu yang diterapkan. Bagi operator sonar kapal selam, suara paus atau lobster merupakan derau, karena suara-suara ini dapat mengacaukan sistem deteksi kapal selam, sehingga tidak diinginkan. Sementara bagi peneliti, perilaku mamalia atau biota laut, seperti suara paus atau lobster adalah suara yang diinginkan (sinyal), bukan derau. Dalam prakteknya, deteksi dan pengukuran bawah air cukup kompleks, rumit, dan bersifat probabilistik. Persamaan sonar dibentuk dari interaksi parameterparameter sonar.

Parameter sonar untuk komponen medium adalah kehilangan perambatan energi suara (transmission loss / TL), aras reverberasi (reverberation level/ $\mathrm{RL}$ ), dan aras derau latar atau lingkungan (ambient-noise level / NLa) untuk kom- ponen target adalah kekuatan target (target strength / TS) dan aras sumber suara (target source level/SLs). Sedangkan untuk komponen peralatan adalah aras sumber yang memancarkan suara (projector source level/SLp), arasswa-derau (selfnoise level/NLs. Pada sistem sonar aktif, instrumen akustik memancarkan gelombang atau pulsa suara. Apabila mengenai target, maka suara tersebut akan dipantulkan atau dihamburbalikkan dan diterima oleh instrumen akustik. Untuk kasus monostatic, dimana posisi sumber suara dan penerima suara terletak pada posisi yang sama), indeks kearah penerima (receiving directivity index/DI), dan ambang deteksi (detection threshold/DT).

\section{SEISMIK}

Ilmu di bidang seismik adalah ilmu yang mempelajari perambatan gelombang seismik dalam medium yang akan memberikan respon terhadap perubahan impedansi dari medium yang dirambati tersebut. Terdapat tiga prinsip aplikasi dalam metode seismik yaitu engineering seismology, exploration seismology, dan 
earthquake seismology. Engineering seismology adalah metode penerapan seismik yang berfungsi untuk mempelajari struktur geologi, batubara dan eksplorasi mineral di kedalaman hingga $1 \mathrm{~km}$ (near-surface).

Exploration seismology merupakan penerapan seismik untuk pencarian hidrokarbon (minyak dan gas) di kedalaman hingga $10 \mathrm{~km}$. Earthquake seismology adalah investigasi struktur kerak bumi dan gempa di kedalaman hingga $100 \mathrm{~km}$ (Neal, 2004). Seismik biasanya diterapkan untuk survei permukaan bawah laut (Lubis et al., 2017). Pada perkembangan terbaru, ilmu di bidang seismik mulai digunakan untuk investigasi di kolom perairan yang kemudian dikenal seismik oseanografi.

Bidang seismik oseanografi merupakan metode seismik yang menggunakan gelombang suara dengan frekuensi rendah (1-200 Hz), yang dipancarkan air gun menuju kolom perairan lalu dipantulkan oleh struktur dari laut dan diterima kembali oleh hydrophones untuk menggambarkan kolom perairan dengan resolusi sekitar 10 m (Ruddick et al., 2009).

Banyaknya penelitian tentang pengolahan pada data seismik untuk meningkatkan kualitas data, seperti penerapan bandpass filter dan automatic gain control (AGC) pada data seismik laut (2D) di Laut Flores (Adi, 2014), pengukuran kecepatan gelombang seismik laut 2D menggunakan prestack time migration dengan Metode Kirchhoff (Reza, 2013). Pengolahan data seismik memiliki beberapa tahapan, dengan salah satu tahapan utama yaitu stack yaitu untuk meningkatkan kualitas SNR. Penelitian ini menggunakan dua metode stack yaitu konvensional dan CRS. Kedua metode ini memiliki kelebihan dan kekurangan (Hertweck et al., 2004).

\section{PENUTUP}

Tulisan ini memberikan informasi yang banyak tentang bagaimana pentingnya teknik deteksi bawah air (hidroakustik, SONAR dan seismik) menggunakan metode hidroakustik dengan aplikasi dalam dunia perikanan dan lautan. Mengetahui parameter SONAR untuk komponen medium dengan kehilangan perambatan energi suara dalam penggunaan penerapan teknologi hidroakustik. Metode ini sangat berguna untuk dunia kelautan dalam menentukan stok ikan, identifikasi objek bawah laut, deteksi minyak di dasar laut yang tidak memerlukan banyak waktu (efisiensi waktu) dan menghasilkan data dengan akurasi yang tinggi.

\section{PUSTAKA}

Adi A.A.W. 2014. Penerapan Bandpass Filter dan Automatic Gain Control (AGC) pada Data Seismik Laut (2D) di Laut Flores [Skripsi]. Bogor (ID): Institut Pertanian Bogor,pp.1-40.

Anderson, J. T., D, Van Holliday, R. Kloser, D. G. Reid, and Y. Simard. 2008. Acoustic seabed classification: cur- 
rent practice and future directions. ICES Journal of Marine Science: Journal du Conseil, 65(6), 1004-1011.

Becker, J. J. and D. T. Sandwell. 2008. Global estimates of seafloor slope from single beam ship soundings. Journal of Geophysical Research: Oceans, 113(C5), pp 355371.

Bozzano, R., L. Castellano and A. Siccardi, 1998. Characterization of submerged aquatic vegetation by a sector-scanning sonar. In: Alippi, A., Canelli, G.B. (Eds.), Proceedings of the 4th European Conference on Underwater Acoustics. Italian. National Research Council, Rome (Italy), pp. 159-164.

Bungo, A., C. Jian, K. Yamaguchi, Y. Sawada, S. Uda and Y. P. Pisarevsky. 1999. Analysis of surface acoustic wave properties of the rotated Y-cut langasite substrate. Japanese journal of applied physics, 38(5S), 3239, pp. 159-164.

Burczynski, J. J., and R. L. Johnson. 1986. Application of dual-beam acoustic survey techniques to limnetic populations of juvenile sockeye salmon (Oncorhynchus nerka). Canadian Journal of Fisheries and Aquatic Sciences, 43(9), 1776-1788.
Coetzee, J. 2000. Use of a shoal analysis and patch estimation system (SHAPES) to characterise sardine schools. Aquatic Living Resources, 13(1), $1-10$.

Furusawa, M. 1998. Prolate Spherodial model for predicting General Trends of Fish Target Strength. J.Acoust.Soc.Am Page 13-24.

Hertwerck, T, C. Jäger, J. Mann Duveneck, and E. Heilmann. 2004. A Seismic Reflection Imaging Workflow based on the Common Reflection Surface (CRS) Stack: Theoretical Background and Case Study. Geophysical Institute University of Karlsruhe Germany.pp. 2032-2035.

Jaya, I. 2011. Penginderaan jauh sumberdaya dan dinamika laut dengan teknologi akustik untuk pembangunan benua maritim Indonesia. Orasi Ilmiah Guru Besar FPIK-IPB. IPB-Press. Bogor.

Johannesson, K. A. and R.B. Mitson. 1983. Fisheries acoustics: a practical manual for aquatic biomass estimation. Food and Agriculture Organization of the United Nations. Pp.1-269.

Lubis, M. Z. and H. M Manik,. 2017. Acoustic systems (split beam echo sounder) to de- 
termine abundance of fish in marine fisheries. Journal of Geoscience, Engineering, Environment, and Technology, 2(1), pp 76-83.

Lubis, M. Z. and W. Anurogo. 2016. Fish stock estimation in Sikka Regency Waters, Indonesia using Single Beam Echosounder (CruzPro fish finder PcFF-80) with hydroacoustic survey method. Aceh Journal of Animal Science, $1(2): 70-78$

Lubis, M. Z., P. D. Wulandari, M. Mujahid, J. Hargreaves and A. V. Pant. 2016. Echo Processing and Identifying Surface and Bottom Layer with Simrad Ek/Ey 500. Journal of Biosensors and Bioelectronics, 7(3), 1000212.

Lubis, M. Z., W. Anurogo, H. Khoirunnisa, S.Irawan, O. Gustin and A. Roziqin. 2017. Using Side-Scan Sonar instrument to Characterize and map of seabed identification target in punggur sea of the Riau Islands, Indonesia. Journal of Geoscience, Engineering, Environment, and Technology, 2(1), pp 1-8.

MacLennan, D. N. and E. J. Simmonds. 1992. Fisheries Acoustic. Chapman \& Hall. New York, New York, USA,pp 176-187.
Misund, O. A. 1997. Underwater acoustics in marine fisheries and fisheries research. Reviews in Fish Biology and Fisheries, 7(1), 1-34.

Neal, A. 2004. Ground-penetrating radar and its use in sedimentology: principles, problems and progress. Earth-science reviews, 66(3), 261-330.

Pasaribu, B.P. 1982. Masalah Tenaga Kerja Teknis Dalam Modernisasi Perikanan Indonesia. Prosiding Workshop Sosial Ekonomi Perikanan Indonesia 1983. Pusat Penelitian Dan Pengembangan Perikanan. Prosiding Workshop Sosial Ekonomi Perikanan Indonesia No.3 Hal 87-93.

Priatna, A. and W. Wijopriono, (2016). Estimasi Stok Sumber Daya Ikan Dengan Metode Hidroakustik Di Perairan Kabupaten Bengkalis. Jurnal Penelitian Perikanan Indonesia, 17(1), pp 1-10.

Pujiyati, S. 2008. Pendekatan metode hidroakustik untuk analisis keterkaitan antara tipe substrat dasar perairan dengan komunitas ikan demersal [Thesis]. Bogor (ID): Institut Pertanian Bogor, pp 1-185.

Pujiyati, S., S. Hartati, and W. Priyono. 2010. 4teffects Of Grain Size, Roughness, And Hard- 
ness Of Sea Floor On Back Scattering Value Based On Hydroacoustic Detection. Jurnal Ilmu dan Teknologi Kelautan Tropis, 2(1), pp 59-67.

Reza, S. 2013. Pengukuran Kecepatan Gelombang Seismik Laut 2D Menggunakan Prestack Time Migration dengan Metode Kirchhoff [Skripsi]. Bogor (ID): Institut Pertanian Bogor, pp 1-34.

Ruddick, B., H. B. Song, C.Z. Dong and L. Pinheiro. 2009. Water column seismic image as maps of temperature gradien. Oceanography. 22(1):192-205.

Simmonds, J. and D. MacLennan. 2005. Underwater sound. Fisheries Acoustics. Theory and Practice, (1945), 20-69.

Simmonds, J. and D. N. MacLennan. 2008. Fisheries acoustics: theory and practice. John Wiley \& Sons, pp 13411348.
Tobito, M. 1990. A new approach to automatic detection of life of coated tool based on acoustic emission measurement. Journal of engineering for industry, 112, 213.

Yasuma, H., K. Sawada, T. Ohshima, K. Miyashita and I. Aoki. 2003. Target strength of mesopelagic lantern fishes (family Myctophidae) based on swimbladder morphology. ICES Journal of Marine Science: Journal du Conseil, 60(3), 584-591.

Zhang, Y. and Z. Xu. 2003. Kinetics of convective crystal dissolution and melting, with applications to methane hydrate dissolution and dissociation in seawater. Earth and Planetary Science Letters, 213(1), 133-148. 